\title{
Guide-Wire Assisted Endobiliary Forceps Biopsy Sampling
}

\author{
Chang-II Kwon', Tae Hoen $\mathrm{Kim}^{2}$ and Kyoung Ah Kim ${ }^{3}$ \\ ${ }^{1}$ Digestive Disease Center, ${ }^{2}$ Department of Pathology, and ${ }^{3}$ Radiology, CHA Bundang Medical Center, CHA University, Seongnam, Korea
}

Biopsy procedures for sampling of the proximal bile duct during endoscopic retrograde cholangiopancreatography (ERCP) can be technically difficult. ${ }^{1}$ Insertion of biopsy forceps into the bile duct is not an easy task and can cause some adverse events. ${ }^{2-4}$ In addition, controlling and positioning the forceps can be difficult during targeted sampling of a designated area. If we could easily insert biopsy forceps into the bile duct and position them at the target area, tissue sampling would not be as challenging during ERCP.

A 59-year-old woman underwent ERCP due to jaundice caused by a proximal biliary stricture that was demonstrated by abdominal computed tomography. On fluoroscopic exam, a $28-\mathrm{mm}$, ovoid filling defect was noted at the proximal bile duct. After biliary sphincterotomy, tissue biopsy was attempted using conventional forceps with a $1.8-\mathrm{mm}$ diameter cup and a $2.5-\mathrm{mm}^{3}$ cup capacity (Optimos ${ }^{\circledR}$ biopsy forceps, Taewoong Medical, Goyang, Korea). However, biopsy procedures can be technically difficult when inserting biopsy forceps into the bile duct, especially when the biopsy is targeted to the side wall of the duct (Fig. 1A). Therefore, we attached a silicone tube on the proximal shaft of the biopsy forceps (Fig. 1C). The silicone tube is a hand-made prototype, and has a small hole that permits passage of a guide-wire and easy passage of forceps into the bile duct (Fig. 1D). Using this biopsy forceps, targeted sampling from the central area of the mass was easily and successfully performed (Fig. 1B). The microscopic examination (Fig. 2) revealed fragments of well-differentiated adenocarcinoma (circle mark) with necrotic debris in the background. The guide-wire assisted method (Fig. 2B) seems superior to the conventional method (Fig. 2A) for sampling sufficient tissue.

Conflicts of Interest

The authors have no financial conflicts of interest.

\section{REFERENCES}

1. Korc P, Sherman S. ERCP tissue sampling. Gastrointest Endosc 2016;84:557-571.

2. Ponchon T, Gagnon F, Berger F, et al. Value of endobiliary brush cytology and biopsies for the diagnosis of malignant bile duct stenosis: results of a prospective study. Gastrointest Endosc 1995;42:565-572.

3. Pugliese V, Conio M, Nicolò G, Saccomanno S, Gatteschi B. Endoscopic retrograde forceps biopsy and brush cytology of biliary strictures: a prospective study. Gastrointest Endosc 1995;42:520-526.

4. Schoefl R, Haefner M, Wrba F, et al. Forceps biopsy and brush cytology during endoscopic retrograde cholangiopancreatography for the diagnosis of biliary stenoses. Scand J Gastroenterol 1997;32:363-368.

\footnotetext{
Received: November 7, 2016 Revised: November 9, 2016

Accepted: November 10, 2016

Correspondence: Chang-Il Kwon

Digestive Disease Center, CHA Bundang Medical Center, 59 Yatap-ro, Bundang-gu, Sungnam-si, Gyeonggi-do 13496, Korea

Tel: +82-31-780-5641, Fax: +82-31-780-5219, E-mail: endoscopy@cha.ac.kr

(cc) This is an Open Access article distributed under the terms of the Creative Commons Attribution Non-Commercial License (http://creativecommons.org/ licenses/by-nc/3.0) which permits unrestricted non-commercial use, distribution, and reproduction in any medium, provided the original work is properly cited.
} 

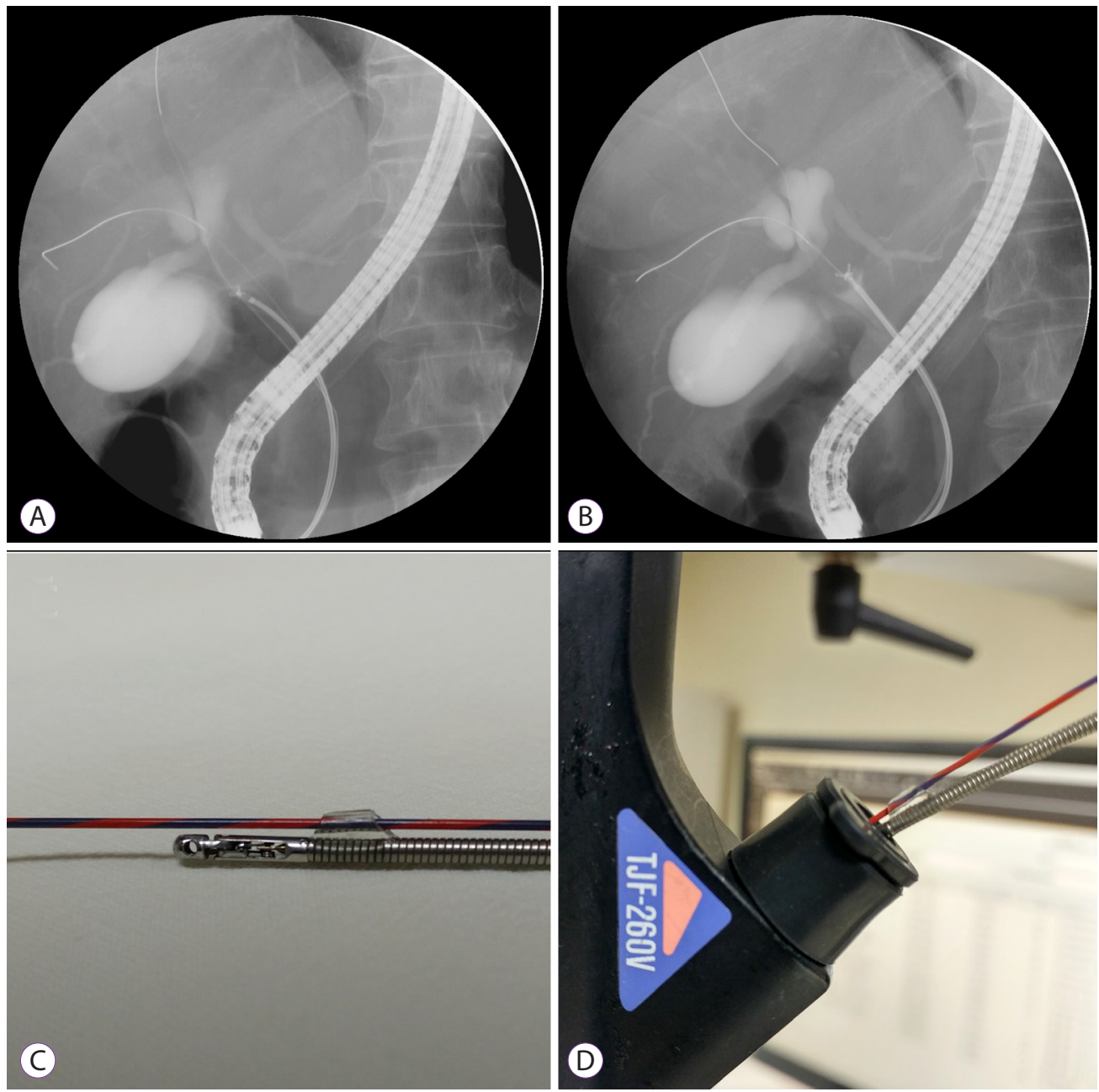

Fig. 1. (A) Cholangiography shows an irregular filling defect in the proximal bile duct with placement of biopsy forceps distal from the mass. (B) Cholangiography shows a filling defect in the proximal bile duct with placement of biopsy forceps in a central area of the defect. The biopsy forceps were easily placed along a guidewire that was passed through a hole in the silicone tube. (C) Attachment of a silicone tube on the proximal shaft of the biopsy forceps. (D) The silicone tube has a small hole that permits passage of a guide-wire and easy passage of forceps into the working channel and bile duct.
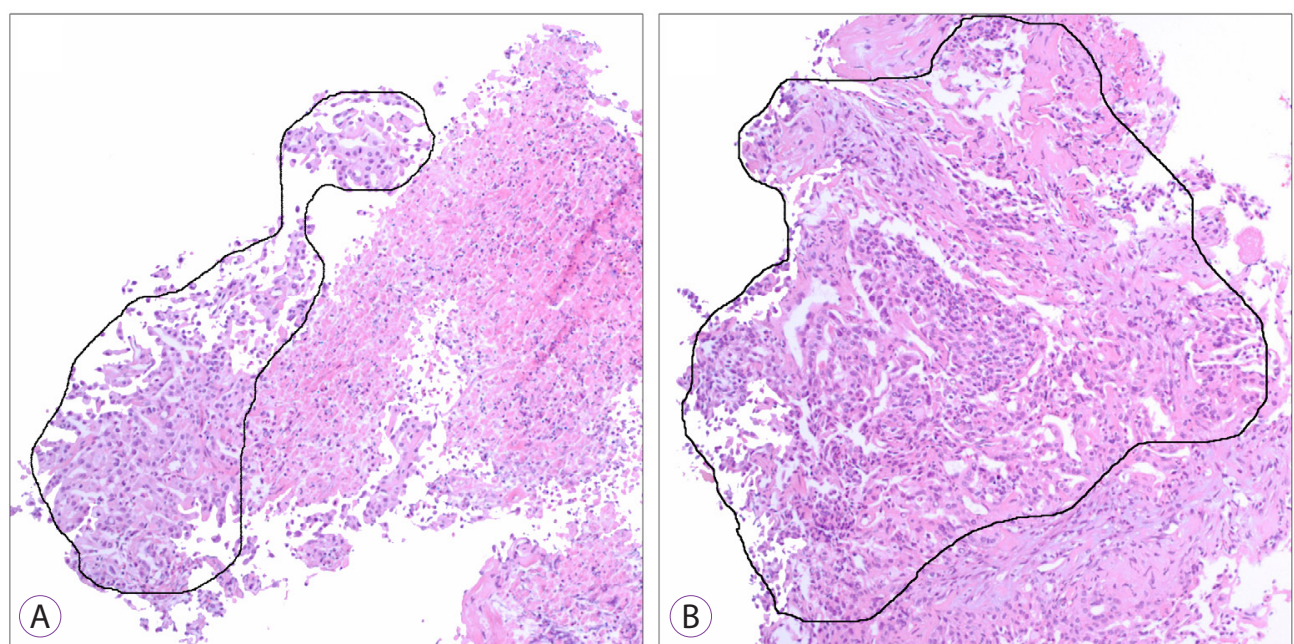

Fig. 2. Low-power microscopic examination reveals a fragment of well-differentiated adenocarcinoma (circle mark) on a background of necrotic debris. The amount of tumor mass obtained by endoscopic retrograde cholangiopancreatography (ERCP) in (A) and (B) indicates that (B) was superior for sampling of sufficient tissue for histologic diagnosis (hematoxylin-eosin stain; $\times 40$ ). 